\title{
The presence of acylated ghrelin during in vitro maturation of bovine oocytes induces cumulus cell DNA damage and apoptosis, and impairs early embryo development
}

\author{
Matias A. Sirini ${ }^{2}$, Juan Mateo Anchordoquy ${ }^{2}$, Juan Patricio Anchordoquy ${ }^{2}$, Ana M. Pascua ${ }^{2}$, \\ Noelia Nikoloff ${ }^{2}$, Ana Carranza ${ }^{2}$, Alejandro E. Relling ${ }^{2,3}$ and Cecilia C. Furnus ${ }^{1}$ \\ IGEVET, Facultad de Ciencias Veterinarias UNLP, La Plata, Buenos Aires, Argentina; and Department of Animal Sciences, \\ The Ohio State University, Wooster, Ohio, USA
}

Date submitted: 24.04.2017. Date revised: 09.07.2017. Date accepted: 14.07.2017

\section{Summary}

The aim of this study was to investigate the effects of acylated ghrelin supplementation during in vitro maturation (IVM) of bovine oocytes. IVM medium was supplemented with 20,40 or $60 \mathrm{pM}$ acylated ghrelin concentrations. Cumulus expansion area and oocyte nuclear maturation were studied as maturation parameters. Cumulus-oocyte complexes (COC) were assessed with the comet, apoptosis and viability assays. The in vitro effects of acylated ghrelin on embryo developmental capacity and embryo quality were also evaluated. Results demonstrated that acylated ghrelin did not affect oocyte nuclear maturation and cumulus expansion area. However, it induced cumulus cell (CC) death, apoptosis and DNA damage. The damage increased as a function of the concentration employed. Additionally, the percentages of blastocyst yield, hatching and embryo quality decreased with all acylated ghrelin concentrations tested. Our study highlights the importance of acylated ghrelin in bovine reproduction, suggesting that this metabolic hormone could function as a signal that prevents the progress to reproductive processes.

Keywords: Active ghrelin, Apoptosis, Cumulus cells, DNA damage, In vitro embryo development

\section{Introduction}

In cattle, dry matter intake is reduced during the last weeks of pregnancy and the early postpartum period due to the metabolic stress suffered by dairy cows. Therefore, cows drive into a negative energy balance (NEB) state as a result of energy loss by milk production that cannot be compensated by energy intake (Bell, 1995). During NEB, many metabolic

\footnotetext{
${ }^{1}$ All correspondence to: Cecilia C. Furnus. IGEVET Instituto de Genética Veterinaria 'Ing. Fernando N Dulout' (UNLP-CONICET LA PLATA), Facultad de Ciencias Veterinarias UNLP, Calles 60 y 118, B1904AMA La Plata, Buenos Aires, Argentina. Tel.: +54 221 4211799. E-mail: cfurnus@fcv.unlp.edu.ar

${ }^{2}$ IGEVET - Instituto de Genética Veterinaria 'Ing. Fernando N Dulout' (UNLP-CONICET LA PLATA), Facultad de Ciencias Veterinarias UNLP, Calles 60 y 118, B1904AMA La Plata, Buenos Aires, Argentina.

${ }^{3}$ Department of Animal Sciences, The Ohio State University, 1680 Madison Ave., Wooster, Ohio 44691, USA.
}

hormones and their receptors alter their concentrations; in particular, plasma acylated ghrelin concentration reaches its maximum (Wertz-Lutz et al., 2006). It has been demonstrated that dairy cows undergo a process called 'nutrient partitioning', emphasizing milk production over reproductive activity throughout the first stage of lactation (Lucy, 2003). Previous reports suggest that NEB induces deleterious effects on cow fertility (Britt, 1992; Butler, 2003; van Knegsel et al., 2005).

Nutritional status is an important factor for regulating endogenous plasma acylated ghrelin concentration (Wertz-Lutz et al., 2006) and reproductive physiology. It is known that metabolic hormones and nutritional signals have a direct effect on the ovary (Tena-Sempere et al., 2002; Dupont et al., 2010). Plasma acylated ghrelin concentration is associated with energy balance (Bradford \& Allen, 2008) and may act as a regulatory signal that links energy balance and reproductive function (Fernandez-Fernandez et al., 2006); it is a gastrointestinal peptide mainly synthesized in 
bovine abomasum (Hayashida et al., 2001), whose expression and actions have been described in various reproductive organs (Gualillo et al., 2001; Gaytan et al., 2003; Tena-Sempere, 2008). Indeed, the ghrelin gene is expressed in multiple tissues exerting endocrine and paracrine effects (van der Lely et al., 2004).

Studies performed in different species have indicated that the addition of acylated ghrelin to mouse embryo culture medium inhibits the development of 2-cell embryos to the hatching blastocyst stage (Kawamura et al., 2003). Also, high acylated ghrelin concentrations (50-500 ng/ml) added to porcine oocyte in vitro maturation (IVM) medium affect the density and distribution of cytoplasmic microtubules (Suzuki et al., 2010). In ovine, a high acylated ghrelin concentration $(250 \mathrm{ng} / \mathrm{ml})$ added during IVM decreased subsequent embryo development to the blastocyst stage (Wang et al., 2013). Dovolou and colleagues (2014) demonstrated that acylated ghrelin accelerates the oocyte maturational process. However, the understanding of ghrelin action on the bovine cumulus-oocyte complex (COC) is still limited.

The aim of this study was to determine whether acylated ghrelin influences bovine COC metabolism and oocyte maturation. For this purpose, we evaluated the effect of increasing acylated ghrelin concentrations added to IVM medium on bovine cumulus expansion and cumulus cell (CC) viability, apoptosis and DNA damage. Furthermore, we evaluated oocyte embryo developmental capacity and embryo quality of COC matured in the presence of increased acylated ghrelin concentrations.

\section{Materials and methods}

\section{Reagents and medium}

All reagents were purchased from Sigma Chemical Co. (St. Louis, MO, USA) unless otherwise indicated. The maturation medium was bicarbonate-buffered TCM-199 supplemented with 10\% (v/v) FCS, $0.2 \mathrm{mM}$ sodium pyruvate, $1 \mathrm{mM}$ glutamine, $1 \mu \mathrm{g} / \mathrm{ml} \mathrm{FSH}, 1$ $\mu \mathrm{g} / \mathrm{ml} 17 \beta$-estradiol and $50 \mu \mathrm{g} / \mathrm{ml}$ kanamycin. The fertilization medium consisted of TALP (Parrish et al., 1986) supplemented with $6 \mathrm{mg} / \mathrm{ml}$ fatty acid free BSA, $20 \mathrm{mM}$ penicillamine, $10 \mathrm{mM}$ hypotaurine and $10 \mu \mathrm{g} / \mathrm{ml}$ heparin sulfate. The culture medium for embryo development consisted of modified synthetic oviduct fluid (SOFm), composed of SOF (Tervit et al., 1972) supplemented with $1 \mathrm{mM}$ glutamine, $2 \% \quad(\mathrm{v} / \mathrm{v})$ BME-essential amino acids, $1 \%(\mathrm{v} / \mathrm{v})$ MEM-non-essential amino acids and $4 \mathrm{mg} / \mathrm{ml}$ fatty acid free bovine serum albumin (BSA; 274-276 $\mathrm{mOsm} / \mathrm{kg}$ ) (Gardner et al., 1994). Acylated ghrelin was purchased from Phoenix Pharmaceuticals Inc., USA (cat. no. 031-52). An annexin-V-FLUOS Staining Kit (cat. no. 11-858-777-001) was purchased from Roche Diagnostics GmbH, Roche Applied Science (Penzberg, Germany). Normal and low melting agaroses were purchased form Carlsbad (Carlsbad, CA, USA).

\section{Oocytes}

Bovine ovaries were obtained from an abattoir and transported to the laboratory in sterile $\mathrm{NaCl}$ solution $(9 \mathrm{~g} / \mathrm{l})$ with streptomycin and penicillin at $37^{\circ} \mathrm{C}$ within $3 \mathrm{~h}$ of slaughter. The ovaries were pooled regardless of the stage of the estrous cycle of the donor. COC were aspirated from 3- to 8-mm follicles using an $18-G$ needle connected to a sterile test tube and to a vacuum line $(50 \mathrm{mmHg})$. Only intact COC with evenly granulated cytoplasm were selected, using a low-power $(\times 20-30$ magnification) stereomicroscope (Nikon SMZ 800, Tokyo, Japan) for in vitro maturation (IVM).

\section{In vitro maturation}

COC were washed twice in TCM-199 buffered with $15 \mathrm{mM}$ HEPES containing $10 \%(\mathrm{v} / \mathrm{v})$ FCS, and twice in IVM medium. COC were then transferred into 50 $\mu 1$ IVM medium pre-equilibrated in a $\mathrm{CO}_{2}$ incubator, either individually (for expansion evaluation) or in groups of 10 COC (for the other assays). Incubations were carried out under mineral oil (Squibb) at $39^{\circ} \mathrm{C}$ in an atmosphere of $5 \% \mathrm{CO}_{2}$ in air with saturated humidity for $24 \mathrm{~h}$. Oocytes were matured in IVM medium supplemented with acylated ghrelin at a final concentration of 0 (Control), 20,40, and $60 \mathrm{pM}$. The criteria for these doses was based on obtaining a medium acylated ghrelin concentration similar to the doses of cows in NEB (Bradford and Allen, 2008).

\section{Cumulus expansion area}

After IVM, cumulus expansion area was measured in each COC using a computerized image-digitizing system with Image ProPlus ${ }^{\circledR} 3.1$ which allows the measurement of irregular areas. The system units were transformed to $\mu \mathrm{m}^{2}$ by calibration with a Maklert chamber. For comparison, each COC area was measured before IVM. For this purpose, 159 COC were matured in three replicates (a separate batch of ovaries for each day).

\section{CC number in COC}

COC, either compact (before IVM) or expanded (after IVM), were dispersed by pipetting the cells up and down several times under a stereomicroscope. The number of cells were estimated by counting in a haemocytometer chamber. In total, 164 COC were used in three replicates. 


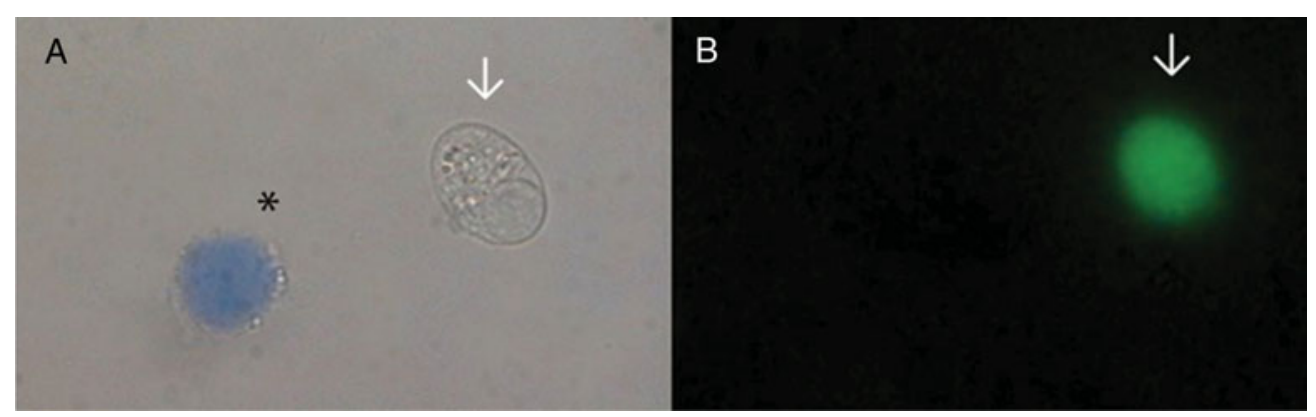

Figure 1 Cumulus cells viability evaluated by trypan blue/fluorescein diacetate assay. $(A)$ Dead cumulus cell $(*)$ shows a characteristic blue staining under white light, whereas a live cell (arrow) is visible in green fluorescence $(B)$.

\section{Oocyte nuclear maturation}

After IVM, oocytes were stripped of surrounding CC and fixed in $4 \%$ formaldehyde. They were washed three times in phosphate-buffered saline (PBS) supplemented with $1 \%$ polyvinylpyrrolidone (PVP). Oocytes were placed in $1 \%$ Triton X-100 overnight, stained with Hoechst 33342, mounted on slides and covered with a coverslip. Germinal vesicle (GV), metaphase I (MI), metaphase II and the first polar body (MII + PB), and degenerate (D) oocytes were determined under an Olympus BX40 epifluorescence microscope with a $\times 40$ magnification objective (Nikon, Tokyo, Japan) equipped with a $365-n m$ excitation filter, a 400-nm barrier filter, and a 400-nm emission filter (Furnus et al., 2008). In total, 454 COC were matured in three replicates.

\section{CC viability}

After maturation, CC viability was evaluated. $\mathrm{Cu}-$ mulus cells were incubated for $10 \mathrm{~min}$ at $37^{\circ} \mathrm{C}$ in PBS medium with $2.5 \mu \mathrm{g} / 1$ fluorescein diacetate fluorochrome and $2.5 \mathrm{~g} / 1$ trypan blue stain. Then, cells were washed in PBS medium and observed under an Olympus BX40 epifluorescence microscope with a 409 fluor objective equipped with a 330-490 $\mathrm{nm}$ excitation filter and a $420-520 \mathrm{~nm}$ emission filter at $\times 200$ magnification. Live CC are visible in green fluorescence, whereas dead ones show a characteristic blue staining under white light (Hoppe \& Bavister, 1984; Fig. 1). In total, 512 COC were matured in three replicates and at least $400 \mathrm{CC}$ per treatment were analyzed in each replicate.

\section{CC apoptosis by annexin-V staining assay}

Annexin- $\mathrm{V}$ is a calcium-dependent phospholipidbinding protein with high affinity for phosphatidyl serine (PS) (van Engeland et al., 1998). Early apoptosis was evaluated by membrane redistribution of PS with the annexin-V-FLUOS Staining Kit. The assay involves simultaneous staining with both annexin-V-FLUOS (green) and the DNA stain propidium iodide (PI, red). Intact cells exclude PI and annexin-V-FLUOS. $\mathrm{CC}$ were classified following the criteria reported by Pläsier et al. (1999) as live (annexin-V negative/PI negative), early apoptotic (annexin-V positive/PI negative), late apoptotic (annexin- $\mathrm{V}$ positive/PI positive), and necrotic (annexin-V negative/PI positive) cells (Fig. 2). Briefly, at the end of IVM, CC were washed twice with PBS and centrifuged at $200 \mathrm{~g}$ for $5 \mathrm{~min}$. Then, the pellet was resuspended in $100 \mu \mathrm{l}$ of annexinV-FLUOS labelling solution (annexin-V + fluorescein, HEPES buffer and PI) and incubated in the dark for 10-15 min at room temperature. In total, 360 COC were matured in three replicates. At least 200 CC per treatment were analyzed in each replicate. Scoring was made at $\times 400$ magnification using an epifluorescence microscope (Olympus BX40) equipped with a 515-560$\mathrm{nm}$ excitation filter.

\section{Comet assay}

At the end of IVM, all oocytes from each treatment were stripped of surrounding CC by repeated pipetting with a narrow-bore glass pipette in TCM 199 buffered with HEPES. CC were washed three times in calcium- and magnesium-free PBS containing $1 \mathrm{mg} / \mathrm{ml}$ PVP, and complete cell disruption was achieved by repeated aspiration using a narrow-bore pipette. The comet assay was performed using the alkaline version described by Singh et al. (1988) with modifications (Tice \& Strauss, 1995). Briefly, slides were covered with a layer of $180 \mu \mathrm{l} 0.5 \%$ normal agarose. Then, $75 \mu \mathrm{l}$ of $0.5 \%$ low melting point agarose was mixed with cells and layered onto the slides, which were immediately covered with cover slips. After agarose solidification at $4^{\circ} \mathrm{C}$ for $10 \mathrm{~min}$, cover slips were removed and slides were immersed overnight in fresh lysis solution at $4^{\circ} \mathrm{C}$. Then, the slides were equilibrated in alkaline solution for $20 \mathrm{~min}$. Electrophoresis was performed for $20 \mathrm{~min}$ at $25 \mathrm{~V}$ and $300 \mathrm{~mA}(1.25 \mathrm{~V} / \mathrm{cm})$. Thereafter, slides were neutralized by washing ( 5 min each) three times with TRIS buffer ( $\mathrm{pH} 7.5)$ and then with distilled 


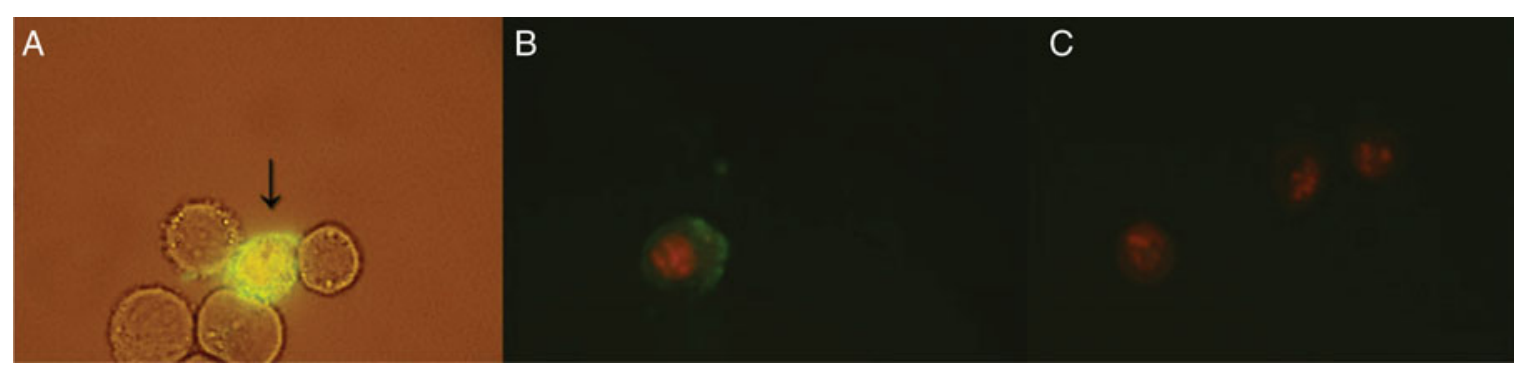

Figure 2 Apoptosis in cumulus cells (CC) stained with annexin-V-FITC and propidium iodide. This assay involves simultaneous staining with both annexin-V-FLUOS (green) and the DNA stain propidium iodide (PI, red). CC were classified as live (annexin-V negative/PI negative), early apoptotic (annexin-V positive/PI negative), late apoptotic (annexin$\mathrm{V}$ positive/PI positive), and necrotic cells (annexin-V negative/PI positive). The cells were analyzed using phase contrast and epifluorescence microscopy: $(A)$ live cells and early apoptotic cell (arrow); $(B)$ late apoptotic cell; and (C) necrotic cells.

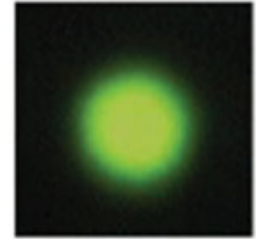

Class 0

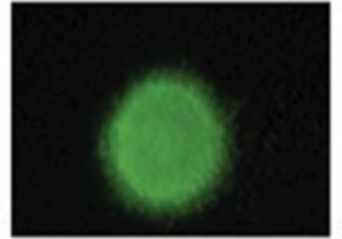

Class 1

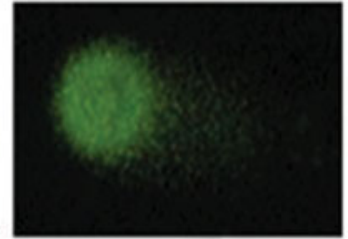

Class 2

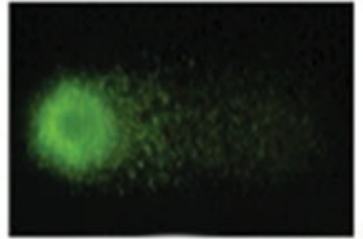

Class 3

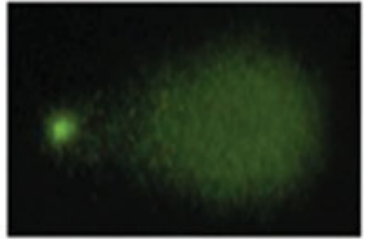

Class 4

Figure 3 DNA damage at individual cumulus cell level. Class 0 (no visible tail), Class 1 (comets with tiny tail), Class 2 (comets with a dim tail), Class 3 (comets with a clear tail) and Class 4 (comets with a clear decrease in the diameter of the head and a clear tail).

water. Slides were stained with 1/1000 SYBR Green I solution (Molecular Probes; Eugene, OR, USA) (Olive, 1999). Scoring was made at $\times 40$ magnification using an epifluorescence microscope (Olympus BX40) equipped with a 515-560-nm excitation filter. Based on the extent of strand breakage, cells were classified according to their tail length into five classes, ranging from Class 0 (no visible tail), Class 1 (comets with a tiny tail), Class 2 (comets with a dim tail), Class 3 (comets with a clear tail), and Class 4 (comets with a clear decrease in the diameter of the head and a clear tail); (Fig. 3). DNA damage was quantified according to Collins and expressed in arbitrary units (Collins, 2004). Genetic damage index (GDI) was calculated using the formula $\mathrm{GDI}=[(\mathrm{I})+2(\mathrm{II})+3(\mathrm{III})+4(\mathrm{IV})] / N_{(0-\mathrm{IV})}$, in which 0 -IV represent the nucleoid type, and $\mathrm{N}_{0}-\mathrm{N}_{\text {IV }}$ represent the total number of nucleoid count (Pitarque et al., 1999). Visual scoring (arbitrary units) is rapid as well as simple, and there is a very close agreement between this method and computer image analysis (percentage DNA in tail) (Collins, 2004). For this purpose, 240 COC were matured in three replicates.

\section{In vitro fertilization (IVF)}

The expanded COC were washed twice in HEPESTALP supplemented with $3 \mathrm{mg} / \mathrm{ml}$ BSA-FAF and placed into $50 \mu \mathrm{l}$ drops of IVF medium under mineral oil. In all experiments, frozen semen from the same bull was used. Two straws containing $4 \times$ $10^{7}$ spermatozoa were thawed in a $37^{\circ} \mathrm{C}$ water bath. Spermatozoa were washed in a discontinuous Percoll gradient prepared by depositing $2 \mathrm{ml}$ of $90 \%$ Percoll under $2 \mathrm{ml}$ of $45 \%$ Percoll in a $15-\mathrm{ml}$ centrifuge tube. Semen samples were deposited on the top of the Percoll gradient and centrifuged at $500 \mathrm{~g}$ for $20 \mathrm{~min}$. The pellet was removed and resuspended in $300 \mu \mathrm{l}$ HEPES-TALP solution and centrifuged at $300 \mathrm{~g}$ for 10 min. After removal of the supernatant, spermatozoa were resuspended in IVF medium, counted in a haemocytometer chamber and further diluted in IVF medium to $1 \times 10^{7}$ spermatozoa $/ \mathrm{ml}$. Final sperm concentration in IVF was $2 \times 10^{6}$ spermatozoa $/ \mathrm{ml}$. Incubations were carried out at $39^{\circ} \mathrm{C}$ in $5 \% \mathrm{CO}_{2}$ in air with saturated humidity for $24 \mathrm{~h}$.

\section{In vitro embryo culture (IVC)}

After IVF, the presumptive zygotes were washed twice in HEPES-SOFm and twice in SOFm, cultured without glucose during the first $24 \mathrm{~h}$ and then cultured for another 7 days with $1.5 \mathrm{mM}$ glucose (Furnus et al., 1997). Embryo culture was carried out in 40 $\mu l$ drops (10 presumptive zygotes/drop) of medium under mineral oil. The embryos were cultured at $39^{\circ} \mathrm{C}$ in an atmosphere composed of $7 \% \mathrm{O}_{2}, 5 \% \mathrm{CO}_{2}$, $88 \% \mathrm{~N}_{2}$ with saturated humidity. The medium was changed every $48 \mathrm{~h}$. At the end of incubations, the 


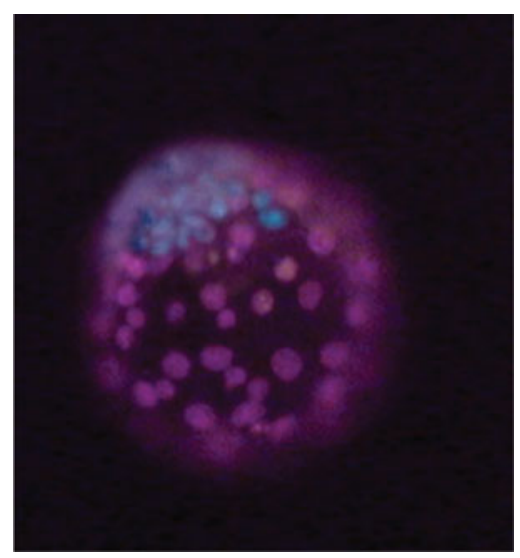

Figure 4 Differential staining of blastocysts. ICM (blue) and TE (red) cells were stained with Hoechst 33342 and propidium iodide respectively.

embryos were evaluated for the morphological stages of development with an inverted microscope (Diaphot; Nikon, Tokyo, Japan).

\section{Differential staining of blastocysts}

Embryo quality (Fukui et al., 1991; O'Hara et al., 2014) was evaluated by total cell number (TCN), inner cell mass (ICM) cell number, and trophectoderm (TE) cell number. For this purpose, TCN, ICM and TE cell numbers were determined in day- 8 blastocysts as described by Thouas et al. (2001). Briefly, before the fixation and staining steps, embryos were exposed to $1 \mu \mathrm{g} / \mathrm{ml} \mathrm{RNase}$ for $1 \mathrm{~h}$ at $38.5^{\circ} \mathrm{C}$. After incubation, blastocysts were washed in $0.01 \mathrm{M}$ PBS containing $1 \mathrm{mg} / \mathrm{ml} \mathrm{PVP}$, stained with $100 \mu \mathrm{g} / \mathrm{ml}$ PI in PBSPVP with $0.2 \%(v / v)$ Triton X-100 for $30 \mathrm{~s}$, repeatedly washed in PBS-PVP, and then fixed in PBS-PVP containing $4 \%(\mathrm{w} / \mathrm{v})$ paraformaldehyde and $1 \mu \mathrm{g} / \mathrm{ml}$ Hoechst 33342 for $15 \mathrm{~min}$. After repeated washing in PBS-PVP, blastocysts were placed on microscope slides with cover slips containing a small drop of glycerol. ICM and TE cell numbers were visualized in an Olympus BX40 epifluorescence microscope with a fluor objective equipped with a 330-490 nm excitation filter and a $420-520 \mathrm{~nm}$ emission filter to distinguish TE cell nuclei (red) from ICM (blue), (Fig. 4). In total, 49 day- 8 blastocysts were used in three replicates.

\section{Statistical analyses}

A completely randomized block design was used. Statistical models included the random effect of block ( $n=3$ or 6 depending on the experiment) and the fixed effect of treatment ( 0 versus 20 verus 40 versus 60 pM ghrelin). CC number, cumulus area and GDI were analyzed with a mixed model (SAS Institute, Cary, NC, USA). Cumulus area before IVM (T0) was used as
Table 1 Effect of ghrelin on meiotic maturation of bovine oocytes in vitro

\begin{tabular}{lcccc}
\hline & \multicolumn{4}{c}{ Ghrelin concentration (pM) } \\
\cline { 2 - 5 } & 0 (Control) & 20 & 40 & 60 \\
\hline Oocytes $(n)$ & 135 & 125 & 100 & 94 \\
GV & 0.0 & 0.0 & 1.0 & 0.0 \\
M I & 5.0 & 8.2 & 1.0 & 6.4 \\
M II + PB & 95.0 & 90.7 & 98.0 & 91.5 \\
D & 0.0 & 1.1 & 0.0 & 2.3 \\
\hline
\end{tabular}

Differences among treatments within each category were not significant $(P>0.05)$.

Bovine COC were incubated in IVM medium with 20, 40 and $60 \mathrm{pM}$ ghrelin during $24 \mathrm{~h}$. Data are expressed as percentage. MI, metaphase I; M II + PB, metaphase II and the first polar body; GV, germinal vesicle; $\mathrm{D}$, degenerate.

covariate in the analysis of cumulus expansion. Oocyte nuclear maturation, oocyte viability, DNA damage and the rates of apoptosis, cleavage, blastocysts and hatching were analyzed by logistic regression using the GENMOD procedure (SAS Institute). TCN per embryo, ICM and TE cell numbers were analyzed by Poisson regression using the GENMOD procedure (SAS Institute) with Poisson distribution and log link. CC number, cumulus area, TCN per blastocyst, ICM, $\mathrm{TE}$ and ICM/TE cell ratio are expressed as mean \pm standard error of the mean (SEM). Oocyte nuclear maturation, oocyte viability, DNA damage and the rates of apoptosis, cleavage, blastocyst and hatching are expressed as percentage. Statistical significance was set at $P<0.05$.

\section{Results}

\section{Effect of ghrelin on oocyte nuclear maturation}

In Experiment 1, nuclear maturation was not significantly different in oocytes matured with $0,20,40$ and 60 $\mathrm{pM}$ acylated ghrelin concentrations (Table $1 ; P \geq 0.05$ ).

\section{Effect of ghrelin on cumulus expansion and CC number in $\mathrm{COC}$}

In Experiment 2, differences in cumulus expansion area after IVM were not significant in COC matured with $0,20,40$ or $60 \mathrm{pM}$ acylated ghrelin concentrations $\left[523,541 \pm 40,748 \mu \mathrm{m}^{2}(n=38) ; 448,626 \pm 39,196 \mu \mathrm{m}^{2}(n\right.$ $=48) 462,383 \pm 40,748 \mu^{2}(n=38) ; 461,749 \pm 42,443$ $\mu \mathrm{m}^{2}(n=35)$, respectively]. CC number per COC either before $(8341.60 \pm 1497.87 ; n=37)$ or after IVM were similar at any acylated ghrelin concentration tested [9409.50 $\pm 1497.87(n=32) ; 8395.8 \pm 1497.87(n=30)$; $9434.3 \pm 1497.87(n=33) ; 11.215 \pm 1497.87(n=32)$ 


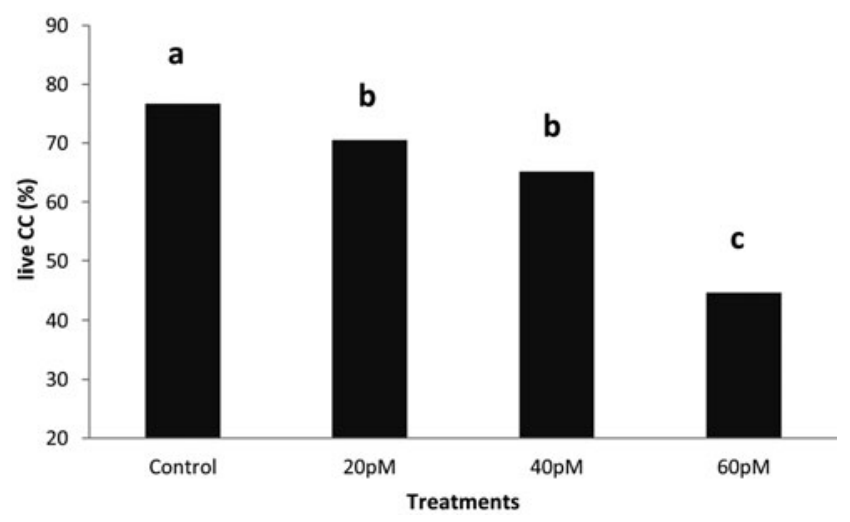

Figure 5 Effect of ghrelin on cumulus cells (CC) viability after IVM. Cumulus cells viability was evaluated with FDA/trypan blue assay. COCs were treated during IVM with different ghrelin concentrations, and harvested after 24 $\mathrm{h}$ of treatment. Results are expressed as percentage of cell viability from three independent experiments. ${ }^{a-c}$ Columns without a common superscript differed $(P<0.05)$.

for $0,20,40$ or $60 \mathrm{pM}$ acylated ghrelin, respectively; $P \geq 0.05]$.

\section{Effect of ghrelin on CC viability}

In Experiment 3, CC viability was significantly higher in COC matured without acylated ghrelin (Control $0 \mathrm{pM}$ acylated ghrelin; $P<0.05)$ as compared with treated ones [76.75\% (307/400); $70.50 \%(282 / 400)$; $65.25 \%(261 / 400)$ and $44.75 \%(179 / 400)$ for Control, 20,40 and $60 \mathrm{pM}$ acylated ghrelin, respectively; $P<0.05]$ (Fig. 5). Statistical differences were found between Control and $20 \mathrm{pM}$, Control and $40 \mathrm{pM}$, Control and 60, 20 and $60 \mathrm{pM}$, and 40 and $60 \mathrm{pM}$. No differences were found between 20 and $40 \mathrm{pM}$ acylated ghrelin (Fig. 5).

\section{Effect of ghrelin on CC apoptosis}

Data of apoptosis in CC exposed to acylated ghrelin concentrations for $24 \mathrm{~h}$ are presented in Table 2 (Experiment 4). The frequency of live cells diminished when acylated ghrelin was added to the medium. However, differences were not statistically significant among acylated ghrelin treatments. Results showed an enhancement of apoptotic cells when CC were treated with 20, 40 and $60 \mathrm{pM}$ acylated ghrelin $(P$ $<0.05)$. Moreover, addition of such acylated ghrelin concentrations increased the frequency of necrotic cells in a nearly dose-dependent manner $(P<0.05)$.

\section{Effect of ghrelin on CC DNA integrity}

Data of comet assay obtained in CC exposed to different ghrelin concentrations for $24 \mathrm{~h}$ (Experiment 5), the proportion of damaged nucleoids and GDI
Table 2 Analysis of apoptosis in cumulus cells (CC) exposed to different ghrelin concentrations measured by annexin-V-FITC/PI

\begin{tabular}{lcccc}
\hline & \multicolumn{4}{c}{ Ghrelin concentration (pM) } \\
\cline { 2 - 5 } CC & 0 (Control) & 20 & 40 & 60 \\
\hline (n) & 600 & 613 & 620 & 601 \\
Live & $74.2^{a}$ & $48.8^{b}$ & $50.2^{b}$ & $47.1^{b}$ \\
Apoptotic & $8.2^{a}$ & $17.6^{b}$ & $14.2^{b}$ & $14.2^{b}$ \\
Necrotic & $17.7^{a}$ & $33.6^{b}$ & $35.6^{b, c}$ & $38.7^{c}$ \\
\hline a-c Lines without a common superscript differed $(P<0.05)$. \\
COC were exposed to 20, 40, and 60 pM ghrelin during IVM. \\
Apoptotic early + late apoptotic CC. \\
Data are presented as percentage.
\end{tabular}

data are presented in Table 3. The frequencies of damaged CC were higher in the presence of 20, 40 and $60 \mathrm{pM}$ acylated ghrelin than in the Control $(P<0.05)$. However, the frequency of DNA damage significantly increased when $C C$ were exposed to $60 \mathrm{pM}$ as compared with 20 and $40 \mathrm{pM}$ acylated ghrelin. GDI increased in the presence of 20 and 60 pM ghrelin with respect to the Control $(P<0.05)$. No significant differences were found in $C C$ treated with $40 \mathrm{pM}$ acylated ghrelin versus the Control.

\section{Effect of acylated ghrelin concentrations during IVM on subsequent embryo development}

In Experiment 6, 1553 oocytes in six replicates were matured and fertilized in vitro (Table 4). There were not significant differences in cleavage rate when acylated ghrelin was added to IVM medium at any concentration. However, there was a diminution in the percentages of blastocyst yield $(P<0.05)$ in oocytes matured with 40 or $60 \mathrm{pM}$ acylated ghrelin. No differences were found between the Control and 20 pM acylated ghrelin. Blastocyst yields with 20, 40 or $60 \mathrm{pM}$ acylated ghrelin were not statistically different. Hatching rates decreased when oocytes were matured with 20,40 or $60 \mathrm{pM}$ ghrelin $(P<0.05)$ (Table 4$)$.

\section{Effect of acylated ghrelin concentrations on embryo quality during IVM}

TCN per blastocyst (Experiment 7) was higher in the Control compared with any of the acylated ghrelin concentrations tested $(P<0.01$; Table 5). Addition of 20,40 or $60 \mathrm{pM}$ acylated ghrelin decreased TCN per blastocyst in a dose-dependent manner. Moreover, both ICM cell number and ICM/TE cell ratio were significantly higher when COC were matured without ghrelin in the IVM medium $(P<0.01$; Table 5$)$. 
Table 3 DNA damage in cumulus cells exposed to ghrelin during $24 \mathrm{~h}$ measured by the comet assay

\begin{tabular}{lcccc}
\hline & \multicolumn{4}{c}{ Ghrelin concentration (pM) } \\
\cline { 2 - 5 } & 0 (Control) & 20 & 40 & 60 \\
\hline Damaged nucleoids, \%* & $79.67^{a}$ & $58.67^{b}$ & $66.00^{b}$ & $49.33^{c}$ \\
0 & $8.67^{a}$ & $12.33^{a, b}$ & $18.67^{b}$ & $15.67^{b}$ \\
I & $4.67^{a}$ & $10.33^{b, c}$ & $6.67^{a, b}$ & $12.33^{c}$ \\
II & $2.33^{a}$ & $5.33^{a, b}$ & $3.00^{a}$ & $7.33^{b}$ \\
III & $4.67^{a}$ & $1.33^{b}$ & $5.67^{a}$ & $15.33^{b}$ \\
IV & $20.34^{a}$ & $41.32^{b}$ & $34.01^{b}$ & $50.66^{c}$ \\
DNA damage,\% (I + II + III + IV) & $0.43^{a}$ & $1.02^{b}$ & $0.63^{a}$ & $1.23^{b}$ \\
GDI & & & & \\
\hline
\end{tabular}

${ }^{\mathrm{a}-\mathrm{c}}$ Lines without a common superscript differed $(P<0.05) .{ }^{*} 0-\mathrm{IV}$ indicate grades of DNA damage as percentage of pooled data from three independent experiment.

${ }^{* *}$ Genetic damage index $(\mathrm{GDI})=(1 \times \mathrm{I}+2 \times \mathrm{II}+3 \times \mathrm{III}+4 \times$ $\mathrm{IV}) /(0+\mathrm{I}+\mathrm{II}+\mathrm{III}+\mathrm{IV})$.

COC were matured during $24 \mathrm{~h}$ (three replicates, 80 COC per replicate, 20 COC per treatment) and at least 200 cells were analyzed per treatment from three replicates performed on different days.

Table 4 Developmental capacity of cattle oocytes matured in vitro with different ghrelin concentration

\begin{tabular}{lcccc}
\hline & \multicolumn{4}{c}{ Ghrelin concentration } \\
\cline { 2 - 5 } & Control & $20 \mathrm{pM}$ & $40 \mathrm{pM}$ & $60 \mathrm{pM}$ \\
\hline Oocyte number & 397 & 376 & 385 & 395 \\
Cleavage rate & $75.7^{a}$ & $78.4^{a}$ & $72.6^{a}$ & $70.9^{a}$ \\
Blastocyst/oocyte rate & $32.0^{a}$ & $28.6^{a, b}$ & $24.8^{b}$ & $23.3^{b}$ \\
Hatching rate & $40.8^{a}$ & $31.0^{b}$ & $27.3^{b}$ & $25.5^{b}$ \\
\hline
\end{tabular}

a-c Values with different letters within each line differed $(P<$ 0.05).

Bovine COC were incubated in IVM medium alone ( $0 \mathrm{pM}$ ghrelin), or 20,40 or 60 pM ghrelin. Cleavage rates were recorded $48 \mathrm{~h}$ after insemination. Data reported for the development to the blastocyst stage included those embryos that progressed to the expanded or hatched blastocyst stages after 8 days in culture. All values for cleavage, development and hatching rates are expressed as percentage (1265 COC in six replicates on different days).

\section{Discussion}

In the present study, we evaluated the effect of acylated ghrelin supplementation at physiological doses on bovine COC during IVM. The effect of 20,40 or 60 pM acylated ghrelin concentrations was tested in IVM of bovine oocytes using oocyte nuclear maturation rate, cumulus expansion area, viability, apoptosis, and DNA damage of CC as quality biomarkers. Additionally, embryo development was analyzed. The results demonstrated that although acylated ghrelin did not affect oocyte nuclear maturation and cumulus expansion area, it induced cell death, apoptosis and
Table 5 Effect of different ghrelin concentrations during in vitro maturation on cell number per blastocyst

\begin{tabular}{lcccc}
\hline & \multicolumn{4}{c}{ Ghrelin concentration (pM) } \\
\cline { 2 - 5 } & 0 (Control) & 20 & 40 & 60 \\
\hline Blastocysts $(n)$ & 11 & 12 & 13 & 13 \\
TCN & $117.1^{a}$ & $105.1^{b}$ & $95.5^{c}$ & $82.1^{d}$ \\
ICM & $31.0^{a}$ & $24.1^{b}$ & $19.6^{c}$ & $14.8^{d}$ \\
TE & $86.1^{a}$ & $81.7^{a, b}$ & $75.8^{b}$ & $67.2^{b}$ \\
ICM/TE cell ratio & $26.5^{a}$ & $22.8^{b}$ & $20.7^{b, c}$ & $18.3^{c}$ \\
\hline
\end{tabular}

${ }^{a-c}$ Values with different letters within each column differed $(P<0.05)$.

TCN, total cell number; TE, trophectoderm; ICM, inner cell mass of day 8 blastocysts developed from oocytes matured in IVM medium alone (0 pM ghrelin) or with 20, 40 and 60 pM ghrelin.

DNA damage in CC. For all assays, the damage increased as a function of the concentration employed. The greatest damage was observed in CC exposed to $60 \mathrm{pM}$ acylated ghrelin. Furthermore, the results demonstrated that while the hormone was not able to affect cleavage rates, the percentage of blastocyst yield, hatching and embryo quality decreased with all acylated ghrelin concentrations in the IVM medium.

Ghrelin is synthesized predominantly in the stomach of non-ruminant animals (Kojima et al., 1999) and in abomasum of ruminants (Hayashida et al., 2001; Thouas et al., 2001). This hormone is a 28-amino acid peptide and was initially characterized as an endogenous ligand for growth hormone secretagogue receptor (GHS-R). Apart from having a wide range 
of physiological roles in many species, including the regulation of food intake and the stimulation of growth hormone secretion (Kojima et al., 1999; Kojima \& Kangawa, 2005), it has been postulated that acylated ghrelin participates in hypothalamicpituitary-gonadal axis regulation (Barreiro \& TenaSempere, 2004; Zhang et al., 2008). Ghrelin gene is expressed in hypothalamus (Kojima et al., 1999; Cowley et al., 2003), pituitary (Korbonits et al., 2001), immune cells (Hattori et al., 2001), lung (Volante et al., 2002) and kidney (Mori et al., 2000). Also, the expression of ghrelin and its receptor has been reported in several reproductive tissues including placenta (Gualillo et al., 2001), testis (Barreiro et al., 2002; Tena-Sempere et al., 2002) and ovary (Caminos et al., 2003; Gaytan et al., 2003) of chicken, rat, pig, sheep, cattle and human (Caminos et al., 2003; Sirotkin et al., 2006; Du et al., 2009; Rak et al., 2009; Deaver et al., 2013). Despite that, information about the effect of acylated ghrelin on bovine oocyte maturation and early embryo development is scarce and contradictory.

CC play a critical role in the oocyte maturation process (Krisher, 2004). The oocyte is surrounded and connected by gap junctions with $\mathrm{CC}$, establishing a structural and functional unit called COC. The COC plays an important role in the regulation of nuclear and cytoplasmic oocyte maturation (Tanghe et al., 2002). CC integrity is considered a good predictor of the ability for further oocyte development (Yuan et al., 2005). Cumulus cell-oocyte communication allows the correct performance of both cell types. Because of this interdependence, any process of cell damage suffered by CC impacts directly into the germ cell itself. Several studies suggest a correlation between CC apoptosis and cleavage rate (Lee et al., 2001). Moreover, Corn and colleagues (2005) showed that a high percentage of CC apoptosis deteriorates the quality of oocytes, resulting in a decreased ability for later embryonic development to the blastocyst stage. Apoptosis occurs when cell damage, including damage to genetic materials, exceeds the capacity of cell repair. DNA damage may be the end product of apoptosis, or responsible for its development (Wang, 2001). Our results are in agreement with this suggestion. It is interesting to note that the presence of $60 \mathrm{pM}$ ghrelin during IVM had a detrimental effect on bovine CC integrity, increasing DNA damage and apoptosis rate and decreasing $C C$ viability. Our findings are consistent with that described by several authors, who observed that high ghrelin concentrations in the IVM medium deteriorate pig and sheep oocytes (Suzuki et al., 2010; Wang et al., 2013). Something worth note is that the working concentrations in the present study were at a physiological concentration, trying to achieve a concentration similar to cow at different energy balance (Bradford \& Allen, 2008), and previous studies (Suzuki et al., 2010; Wang et al., 2013) were with doses at a pharmacological concentration. Previous reports suggest that ghrelin could play an important role in programmed cell death. In this sense, Kheradmand and colleagues (Arash et al., 2014) indicate that ghrelin is involved in the control of gonadal functions, apoptosis and proliferation in the rat ovary. Furthermore, Rui-Xia Bai and colleagues (2013) have suggested that ghrelin could have a potential regulatory role in apoptotic function in sheep oocytes.

Oocyte maturation is a critical phenomenon which depends on the ability of subsequent embryonic development (Krisher et al., 2004). Matured oocytes can be fertilized, develop to the blastocyst preimplantation stage and give viable fetuses (Moor \& Trounson, 1977). Maturation is the result of a complex interaction among the oocyte, CC and the environment that surrounds them (Moor et al., 1998). Although the presence of 20,40 or $60 \mathrm{pM}$ acylated ghrelin in the microenvironment surrounding $\mathrm{COC}$ did not affect nuclear maturation, it caused CC damage and affected the capacity of the oocyte to undergo embryo development, as evidenced by decreasing blastocyst rates. Results of a study performed in pig oocytes showed that high ghrelin concentrations during IVM inhibited oocyte nuclear maturation and affected oocyte cytoskeletal distribution and density (Suzuki et al., 2010). Moreover, Seino and colleagues (Seino et al., 2002) demonstrated that increased CC DNA damage during human oocyte maturation reduced fertility rate and blastocyst quality assessed as fragmentation of the embryo mass. In the present study, ghrelin supplementation during bovine oocyte IVM decreased embryo quality assessed as hatching rates and cell number/blastocyst. Cell numbers in TE and ICM, or in both cell populations of blastocysts, are indicators of embryo growth and viability (Van Soom et al., 1997; Kawamura et al., 2003). In our study, ghrelin decreased TCN of blastocysts as a result of a reduction of both ICM and TE cell numbers. Similar results were observed when ghrelin was added to mouse embryo culture medium. Kawamura and colleagues (2003) found that ghrelin inhibited mouse preimplantation embryo development from two-cell stage embryo to the blastocyst, fully expanded blastocyst, and hatched blastocyst in vitro in a dosedependent manner. Dovolou and colleagues (2014) suggested that incubation of bovine COC with 237.38 pM ghrelin for $24 \mathrm{~h}$ caused oocyte overmaturation, but oocytes matured for $18 \mathrm{~h}$ under the same conditions reached MII, the cumulus layer expanded more that the Control, and differences in the expression of various genes with respect to the controls were detected. Dovolou et al. (2014), however, observed that the formed blastocysts had a higher hatching rate 
compared with the Control. It should be noted that we found a negative ghrelin-induced effect during IVM with ghrelin concentrations 11.8 lower than those used by Dovolou et al., (2014), suggesting a high sensitivity of the in vitro system to even lower ghrelin concentrations than the physiological ones measured in animals.

Our results are in agreement with the points made by others author, who suggest that certain metabolic hormones and neuropeptides could act as responsible nutritional signals regulating reproductive function (Evans \& Anderson, 2012; Lorenzi et al., 2009; TenaSempere, 2008). Our study also highlights the importance of acylated ghrelin on bovine reproduction. We thus suggest that this metabolic hormone could function as a signal that prevents the progress to reproductive processes in which energy nutrients into milk production and survival of breeding are prioritized.

In conclusion, the presence of ghrelin in IVM medium induces CC DNA damage and apoptosis during bovine oocyte maturation in vitro, and impairs subsequent early embryo development. Consequently, the results suggest that the action of low ghrelin concentrations during oocyte maturation may have a negative influence on cytoplasmic maturation affecting negatively early embryonic development.

\section{Acknowledgements}

We are grateful to the staff of Frigorífico Gorina S.A. for providing bovine ovaries, and to Centro de Inseminación Artificial La Elisa S.A. (CIALE) for providing bovine frozen semen. We also thank A. Di Maggio for manuscript correction.

\section{Funding}

This work was supported by grants from Agencia Nacional de Promoción Científica y Tecnológica de la República Argentina (PICT BID 1972-2013), Ministerio de Ciencia, Tecnología e Innovación Productiva de la Nación Argentina.

\section{References}

Arash, K., Omid, D. \& Masoud, A. (2014). Ghrelin is a regulator of cellular apoptosis and proliferation in the rat ovary. Int. J. Pept. Res. Ther. 20, 289-98.

Barreiro, M.L., Gaytan, F., Caminos, J.E., Pinilla, L., Casanueva, F.F., Aguilar, E., Dieguez, C. \& Tena-Sempere, M. (2002). Cellular location and hormonal regulation of ghrelin expression in rat testis. Biol. Reprod. 67, 1768-76.
Barreiro, M.L. \& Tena-Sempere, M. (2004). Ghrelin and reproduction: a novel signal linking energy status and fertility? Mol. Cell. Endocrinol. 226, 1-9.

Bell, A.W. (1995). Regulation of organic nutrient metabolism during transition from late pregnancy to early lactation. J. Anim. Sci. 73, 2804-19.

Bradford, B.J. \& Allen, M.S. (2008). Negative energy balance increases periprandial ghrelin and growth hormone concentrations in lactating dairy cows. Domest. Anim. Endocrinol. 34, 196-203.

Britt, J.H. (1992). Impacts of early postpartum metabolism on follicular development and fertility. Bov. Proc. 24, 39-43.

Butler, W.R. (2003). Energy balance relationships with follicular development., ovulation and fertility in postpartum dairy cows. Livestock Prod. Sci. 83, 211-8.

Caminos, J.E., Tena-Sempere, M., Gaytan, F., SanchezCriado, J.E., Barreiro, M.L., Nogueiras, R., Casanueva, F.F., Aguilar, E. \& Dieguez, C. (2003). Expression of ghrelin in the cyclic and pregnant rat ovary. Endocrinology 144, 1594602.

Collins, A.R. (2004). The comet assay for DNA damage and repair: principles., applications., and limitations. Mol. Biotechnol. 26, 249-61.

Corn, C.M., Hauser-Kronberger, C., Moser, M., Tews, G. \& Ebner, T. (2005). Predictive value of cumulus cell apoptosis with regard to blastocyst development of corresponding gametes. Fertil. Steril. 84, 627-33.

Cowley, M.A., Smith, R.G., Diano, S., Tschöp, M., Pronchuk, N., Grove, K.L., Strasburger, C.J., , Bidlingmaier, M., Esterman, M., Heiman, M.L., García-Segura, L.M., Nillni, E.A., Mendez, P., Low, M.J., Sotonyi, P., Friedman, J.M., Liu, H., Pinto, S., Colmers, W.F., Cone, R.D. \& Horvath, T.L. (2003). The distribution and mechanism of action of ghrelin in the CNS demonstrates a novel hypothalamic circuit regulating energy homeostasis. Neuron 37649-61.

Deaver, S.E., Hoyer, P.B., Dial, S.M., Field, M.E., Collier, R.J. \& Rhoads, M.L. (2013). Localization of ghrelin and its receptor in the reproductive tract of Holstein heifers. $J$. Dairy Sci. 96,150-7.

Dovolou, E., Messinis, I.E., Periquesta, E., Dafopoulos, K., Gutierrez-Adan, A. \& Amiridis, G.S. (2014). Ghrelin accelerates in vitro maturation of bovine oocytes. Reprod. Domest. Anim. 49, 665-72.

Du, C., Xilingaowa, C.G., Wang, C., Li, H., Zhao, Y. \& Siqingaowa, C.J. (2009). Expression of the orexigenic peptide ghrelin in the sheep ovary. Domest. Anim. Endocrinol. 36, 89-98.

Dupont, J., Maillard, V., Coyral-Castel, S., Rame, C. \& Froment, P. (2010). Ghrelin in female and male reproduction. Int. J. Pep. Article ID 158102, 8 pp.

Evans, J.J. \& Anderson, G.M. (2012). Balancing ovulation and anovulation: integration of the reproductive and energy balance axes by neuropeptides. Hum. Reprod. Update 3, 313-32.

Fernandez-Fernandez, R., Martini, AC., Navarro, V.M., Castellano, J.M., Dieguez, C., Aguilar, E., Pinilla, L. \& Tena-Sempere, M. (2006). Novel signals for the integration of energy balance and reproduction. Mol. Cell. Endocrinol. 25, 127-32.

Fukui, Y., McGowan, L.T., James, R.W., Pugh, P.A. \& Tervit, H.R. (1991). Factors affecting the in. vitro development to 
blastocysts of bovine oocytes matured and fertilized in vitro. J. Reprod. Fertil. 92, 125-31.

Furnus, C., de Matos, D., Martínez, A. \& Matkovic, M. (1997). Effect of glucose on embryo quality and postthaw viability of in-vitro-produced bovine embryos. Theriogenology 47, 481-90.

Furnus, C.C., de Matos, D.G., Picco, S., Garcĺa, P.P., Inda, A.M., Mattioli, G. \& Errecalde, A.L. (2008). Metabolic requirements associated with GSH synthesis during in vitro maturation of cattle oocytes. Anim. Reprod. Sci. 109, 88-99.

Gardner, D.K., Lane, M., Spitzer, A. \& Batt, PA. (1994). Enhanced rates of cleavage and development for sheep zygotes cultured to the blastocyst stage in vitro in the absence of serum and somatic cells: amino acids, vitamins, and culturing embryos in groups stimulate development. Biol. Reprod. 50, 390-40.

Gaytan, F., Barreiro, M.L., Chopin, L.K., Herington, A.C., Morales, C., Pinilla, L., Casanueva, F.F., Aguilar, E., Dieguez, C. \& Tena-Sempere, M. (2003). Immunolocalization of ghrelin and its functional receptor., type 1a growth hormone secretagogue receptor., in the cyclic human ovary. J. Clin. Endocrinol. Metab. 88, 879-87.

Gualillo, O., Caminos, J. \& Blanco, M. (2001). Ghrelin, a novel placental- derived hormone. Endocrinology 142, 788-94.

Hattori, N., Saito, T., Yagyu, T., Jiang, B.H., Kitagawa, K. \& Inagaki, C. (2001). GH, GH receptor, GH secretagogue receptor, and ghrelin expression in human $\mathrm{T}$ cells, B cells, and neutrophils. J. Clin. Endocrinol. Metab. 86, 4284-91.

Hayashida, T.K., Murakami, K., Mogi, M., Nishihara, M., Nakazato, M.S., Mondal, Y., Horii, M., Kojima, K., Kangawa, K. \& Murakami, N. (2001). Ghrelin in domestic animals: distribution in the stomach and its possible role. Domest. Anim. Endocrinol. 21, 17-24.

Hoppe, R. \& Bavister, B. (1984). Evaluation of the fluorescein diacetate (FDA) vital dye viability test with hamster and bovine embryos. Anim. Reprod. Sci. 6, 323-5.

Kawamura, K., Sato, N., Fukuda, J., Kodama, H., Kumegai, J., Tanikawa, H., Nakamura, A., Honda, Y., Sato, T. \& Tanaka, T. (2003). Ghrelin inhibits the development of mouse preimplantation embryos in vitro. Endocrinology 144, 2623-33.

Kojima, M. \& Kangawa, K. (2005). Ghrelin: structure and function. Physiol. Rev. 85, 495-522.

Kojima, M., Hosoda, H., Date, Y., Nakazato, M., Matsuo, H. \& Kangawa, K. (1999). Ghrelin is a growth-hormonereleasing acylated peptide from stomach. Nature 402, 656-60.

Korbonits, M., Bustin, S.A., Kojima, M., Jordan, S., Adams, E.F., Lowe, D.G., Kangawa, K. \& Grossman, A.B. (2001). The expression of the growth hormone secretagogue receptor ligand ghrelin in normal and abnormal human pituitary and other neuroendocrine tumors. J. Clin. Endocrinol. Metab. 86, 881-7.

Krisher, R.L. (2004). The effect of oocyte quality on development. J. Anim. Sci. 82, 14-23.

Lee, K.S., Joo, B.S., Na, Y.J., Yoon, M.S., Choi, O.H. \& Kim, W.W. (2001). Cumulus cell apoptosis as an indicator to predict the quality of oocytes and the outcome of IVF-ET. J. Assist. Reprod. Genet. 18, 490-8.
Lorenzi, T., Meli, R., Marzioni, D., Morroni, M., Baragli, A., Castellucci, M., Gualillo, O. \& Muccioli, G. (2009). Ghrelin: a metabolic signal affecting the reproductive system. Cytokine Growth Factor Rev. 20, 137-52.

Lucy, M. (2003). Mechanisms linking nutrition and reproduction in postpartum cows. Reprod. Suppl. 61, 415-7.

Moor, R.M., Dai, Y., Lee, C. \& Fulka, J. (1998). Oocyte maturation and embryonic failure. Hum. Reprod. Update 4 223-6.

Moor, R.M. \& Trounson, A.O. (1977). Hormonal and follicular factors affecting maturation of sheep oocytes in vitro and their subsequent developmental capacity. J. Reprod. Fert. 49, 101-9.

Mori, K., Yoshimoto, A., Takaya, K., Hosoda, K., Ariyasu, H., K Yahata., Mukoyama, M., Sugawara, A., Hosoda, H., Kojima, M., Kangawa, K. \& Nakao, K. (2000). Kidney produces a novel acylated peptide, ghrelin. FEBS Lett. 486, 213-6.

O’Hara, L., Forde, N., Kelly, A.K. \& Lonergan, P. (2014). Effect of bovine blastocyst size at embryo transfer on day 7 on conceptus length on day 14: can supplementary progesterone rescue small embryos? Theriogenology 81, 1123-8.

Olive, P.L. (1999). DNA damage and repair in individual cells: applications of the comet assay in radiobiology. Int. J. Radiat. Biol. 75, 395-405.

Parrish, J.J., Susko-Parrish, J., Leibfried-Rutledge, M.L., Critser, E.S., Eyestone, W.H. \& First, N.F. (1986). Bovine in vitro fertilization with frozen-thawed semen. Theriogenology 25, 591-600.

Pitarque, M., Vaglenov, A., Nosko, M., Hirvonen, A., Norppa, H. \& Creus, A. (1999). Evaluation of DNA damage by the Comet assay in shoe workers exposed to toluene and other organic solvents. Mutat. Res. 441, 115-27.

Pläsier, B., Lloyd, D.R., Paul, G.C., Thomas, C.R. \& Al-Rubeai, M. (1999). Automatic image analysis for quantification of apoptosis in animal cell culture by annexin-V affinity assay. J. Immunol. Methods 229, 81-95.

Rak, A., Szczepankiewicz, D. \& Gregoraszczuk, E.L. (2009). Expression of ghrelin receptor., GHSR-1a, and its functional role in the porcine ovarian follicles. Growth Horm. IGF Res. 19, 68-76.

Rui-Xia, B., Peng, W.Z. \& Gui-fang, C. (2013). Effect of ghrelin on the expression of bcl-20 BAX mRNA in in vitro maturation ovine oocytes. Indian J. Anim. Sci. 83, 37-9.

Seino, T., Saito, H., Kaneko, T., Takahashi, T., Kawachiya, S. \& Kurachi, H. (2002). Eight-hydroxy-2'-deoxyguanosine in granulosa cells is correlated with the quality of oocytes and embryos in an in vitro fertilization-embryo transfer program. Fertil. Steril. 77, 1184-90.

Singh, N.P., McCoy, M.T., Tice, R.R. \& Schneider, E.L. (1988). A simple technique for quantitation of low levels of DNA damage in individual cells. Exp. Cell. Res. 175,184-91.

Sirotkin, A.V., Grossmann, R., María-Peon, M.T., Roa, J., Tena-Sempere, M. \& Klein, S. (2006). Novel expression and functional role of ghrelin in chicken ovary. Mol. Cell. Endocrinol. 26, 257-8.

Suzuki, H., Sasaki, Y., Shimizu, M., Matsuzaki, M., Hashizume, T. \& Kuwayama, H. (2010). Ghrelin and leptin did not improve meiotic maturation of porcine oocytes cultured in. vitro. Reprod. Domest. Anim. 45, 927-30. 
Tanghe, S., Van Soom, A., Nauwynck, H., Coryn, M. \& de Kruif, A. (2002). Minireview: Functions of the cumulus oophorus during oocyte maturation, ovulation, and fertilization. Mol. Reprod. Dev. 61, 414-24.

Tena-Sempere, M., Barreiro, M.L., Gonzalez, L.C., Gaytan, F., Zhang, F.P., Caminos, J.E., Pinilla, L., Casanueva, F.F., Dieguez, C. \& Aguilar, E. (2002). Novel expression and functional role of ghrelin in rat testis. Endocrinology 143, 717-25.

Tena-Sempere, M. (2008). Ghrelin and reproduction: ghrelin as novel regulator of the gonadotropic axis. Vitam. Horm. 77, 285-90.

Tervit, H.R., Whittingham, D.G. \& Rowson, L.E.A. (1972). Successful culture in vitro of sheep and cattle ova. J. Reprod. Fertil. 30, 93-7.

Thouas, G.A., Korfiatis, N.A., French, A.J., Jones, G.M. \& Trounson, A.O. (2001). Simplified technique for differential staining of inner cell mass and trophectoderm cells of mouse and bovine blastocysts. Reprod. Biomed. Online 3, 25-9.

Tice, R.R. \& Strauss, G.H. (1995). The single cell gel electrophoresis/comet assay: a potential tool for detecting radiation-induced DNA damage in humans. Stem Cells 1, 207-14.

van der Lely, A.J., Tschöp, M., Heiman, M.L. \& Ghigo, E. (2004). Biological, physiological, pathophysiological, and pharmacological aspects of ghrelin. Endocr. Rev. 25, 426-57.

van Engeland, M., Nieland, L.J., Ramaekers, F.C., Schutte, B. \& Reutelingsperger, C.P. (1998). Annexin-V-affinity assay: a review on an apoptosis detection system based on phosphatidylserine exposure. Cytometry 31, 1-9. van Knegsel, A.T., van den Brand, H., Dijkstra, J., Tamminga, S. \& Kemp, B. (2005). Effect of dietary energy source on energy balance, production, metabolic disorders and reproduction in lactating dairy cattle. Reprod. Nutr. Dev. 45, 665-88.

Van Soom, A., Ysebaert, M.T. \& de Kruif, A. (1997). Relationship between timing of development., morula morphology and cell allocation to inner cell mass and trophectoderm in in-vitro produced bovine embryos. Mol. Reprod. Dev. 47, 47-56.

Volante, M., Fulcheri, E., Allia, E., Cerrato, M., Pucci, A. \& Papotti, M. (2002). Ghrelin expression in fetal, infant, and adult human lung. J. Histochem. Cytochem. 50,1013-21.

Wang, J.Y.J. (2001). DNA damage and apoptosis. Cell Death Differ. 8, 1047-8.

Wang, Z., Lin, P. \& Yu, S. (2013). Effects of ghrelin on developmental competence and gene expression of in vitro fertilized ovine embryos. Theriogenology 79, 695-701.

Wertz-Lutz, A.E., Knight, T.J., Pritchard, R.H., Daniel, J.A., Clapper, J.A. \& Smart, A.J. (2006). Circulating ghrelin concentrations fluctuate relative to nutritional status and influence feeding behavior in cattle. Anim. Sci. 84, 3285-300.

Yuan, Y.Q., Van Soom, A., Leroy, J.L., Dewulf, J., Van Zeveren, A., de Kruif, A. \& Peelman, L.J. (2005). Apoptosis in cumulus cells., but not in oocytes., may influence bovine embryonic developmental competence. Theriogenology 63, 2147-63.

Zhang, W., Lei, Z., Su, J. \& Chen, S. (2008). Expression of ghrelin in the porcine hypothalamo-pituitary-ovary axis during the estrous cycle. Anim. Reprod. Sci. 109, 356-67. 